Cardiology 2020;145:615-622

DOI: $10.1159 / 000505317$
Received: May 14, 2019

Accepted after revision: December 9, 2019

Published online: August 23, 2020

\title{
Advances in Cardiac Computed Tomography Functional Imaging Technology
}

\author{
Xu-Wei Tian Ai-Lin Ma Ren-Bing Zhou Liu-Jiang Jiang Yue Hao \\ Xiao-Guang Zou \\ Department of Radiology, Department of Medical Imaging, The First People's Hospital Kashgar Region, Kashgar, China
}

\section{Keywords}

Tomography · Computed tomography functional imaging · Cardiovascular disease · Cardiomyopathy · Imaging mode

\begin{abstract}
Cardiovascular disease (CVD) is the leading cause of death among patients in China, and cardiac computed tomography $(\mathrm{CT})$ is one of the most commonly used examination methods for CVD. Coronary artery CT angiography can be used for the morphologic evaluation of the coronary artery. At present, cardiac CT functional imaging has become an important direction of development of CT. At present, common CT functional imaging technologies include transluminal attenuation gradient, stress dynamic CT myocardial perfusion imaging, and CT-fractional flow reserve. These three imaging modes are introduced and analyzed in this review.
\end{abstract}

(c) 2020 S. Karger AG, Basel

\section{Introduction}

Cardiovascular disease (CVD) is the leading cause of death among patients in China [1], and cardiac computed tomography (CT) is one of the most commonly used examination methods for CVD. Since multislice helical CT has been used in clinical practice in 1998, CT hardware and software technology has made great progress. Furthermore, cardiac CT has become more and more mature, and has been widely used as the best examination method for patients with suspected coronary heart disease at present [2]. Although cardiac CT examination is excellent in the morphological evaluation of coronary arteries, evaluation of cardiac function is always the short board of CT cardiac imaging. With the continuous progress of imaging and postprocessing technology, cardiac CT functional imaging technologies are increasingly being used in clinical assessments and decision-making. Among these technologies, transluminal attenuation gradient (TAG), stress dynamic CT myocardial perfusion imaging, and CT-fractional flow reserve (FFR) have been frequently reported. In this review, the new progress of these three cardiac CT functional imaging methods was comprehensively introduced. This study aims to review and compare the differences among TAG, stress dynamic CT myocardial perfusion imaging, and CT-FFR.

\section{Transluminal Attenuation Gradient}

TAG was first proposed by Steigner et al. [3]. TAG refers to the degree of change in the CT value in the lumen of the segment of the coronary artery, beginning from the coronary artery orifice. Generally, $10 \mathrm{~mm}$ is used as an

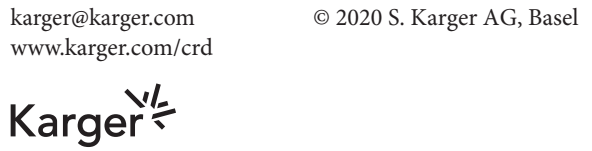



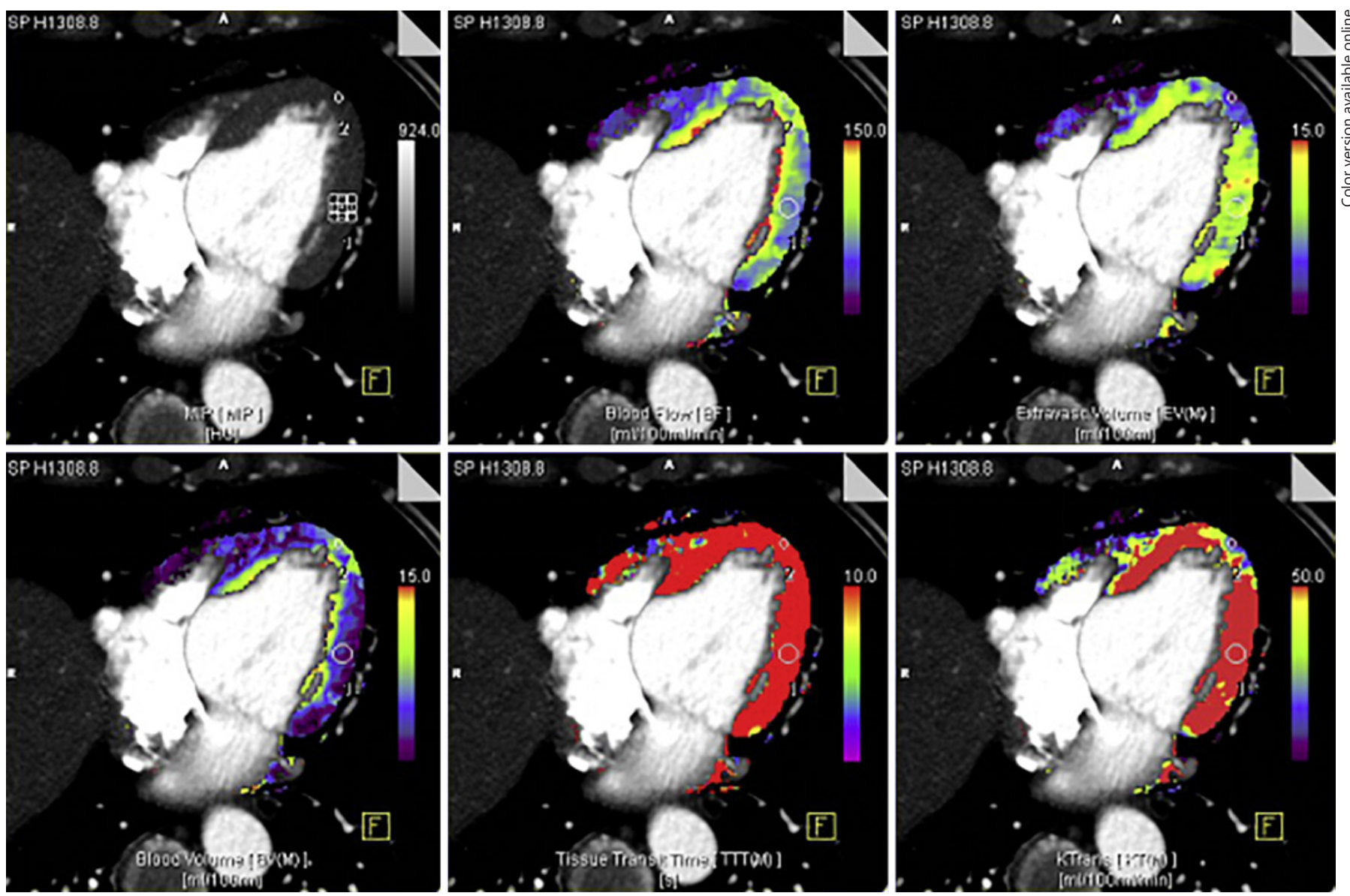

Fig. 1. Result of stress dynamic CT myocardial perfusion imaging.

interval length to measure the $\mathrm{CT}$ value. The specific measurement methods are as follows. First, the cross-sectional images of the coronary artery perpendicular to the vascular centerline are reconstructed. In the segment of the coronary artery beginning from the orifice where the cross section is larger than $2 \mathrm{~mm}^{2}$, the CT value in the lumen is measured at every $5 \mathrm{~mm}$. Early studies have revealed that TAG generally assumes a linear trend. If there is a functional stenosis in the coronary arteries, the TAG in the lumen of the stenotic segment of the coronary artery will significantly decrease.

Choi et al. [4] revealed that compared with invasive angiography, the change in TAG is consistent with the severity of coronary artery stenosis, which helps to improve the classification of the severity of coronary artery stenosis, especially in patients with severe calcification of the coronary artery. In a subsequent study, Choi et al. [5] compared the results of TAG to FFR, with FFR $<0.8$ as the boundary value, and used TAG and coronary artery CTA (CCTA) com- bined with the semi-quantitative method to evaluate the degree of coronary artery stenosis. It was found that the area under the receiver operating characteristic (ROC) curve significantly increased. However, the combination of these two did not significantly improve the reclassification of coronary artery stenosis. Furthermore, Yoon et al. [6] reported that compared to FFR, the area under the ROC curve of TAG was larger, but there was no statistical difference when compared to coronary arteries with a calcified plaque. Moreover, Wong et al. [7] reported that the critical value of TAG was $-15.1 \mathrm{HU} / 10 \mathrm{~mm}$, the sensitivity was $77 \%$, the specificity was $74 \%$, the positive predictive value was $67 \%$, and the negative predictive value was $83 \%$.

Compared with other cardiac CT functional imaging methods, TAG does not require additional scanning or complex postprocessing. Furthermore, compared with invasive FFR, TAG checks are safer, and the risk and financial burden of the examinees are lower. However, TAG also has great limitations: for patients with diffuse calcifi- 
Table 1. Diagnostic efficiency of dynamic myocardial perfusion in different studies

\begin{tabular}{|c|c|c|c|c|c|c|c|}
\hline Research & Time & $\begin{array}{l}\text { Reference } \\
\text { criteria }\end{array}$ & $\begin{array}{l}\text { Sensitivity, } \\
\%\end{array}$ & $\begin{array}{l}\text { Specificity, } \\
\%\end{array}$ & $\begin{array}{l}\text { Positive } \\
\text { prediction, \% }\end{array}$ & $\begin{array}{l}\text { Negative } \\
\text { prediction, \% }\end{array}$ & AUC \\
\hline Bom et al. [9] & 2019 & SPECTICA & 83 & 78 & 79 & 82 & NA \\
\hline Bastarrika et al. [10] & 2010 & MRI & 86 & 98 & 94 & 96 & NA \\
\hline Weininger et al. [11] & 2012 & SPECT & 84 & 92 & 88 & 92 & NA \\
\hline Wang et al. [12] & 2012 & SPECTICA & 85 & 92 & 55 & 98 & NA \\
\hline Greif et al. [13] & 2013 & Invasive FFR & 95 & 74 & 48 & 98 & NA \\
\hline Huber et al. [14] & 2013 & Invasive FFR & 76 & 100 & 100 & 90 & 0.86 \\
\hline Rossi et al. [15] & 2014 & Invasive FFR & 88 & 90 & 77 & 95 & 0.95 \\
\hline Wong et al. [17] & 2014 & Invasive FFR & 76 & 89 & NA & NA & 0.84 \\
\hline Yang et al. [18] & 2015 & Invasive FFR & 80 & 95 & NA & NA & 0.88 \\
\hline Coenen et al. [19] & 2017 & Invasive FFR & 73 & 68 & 67 & 74 & 0.78 \\
\hline
\end{tabular}

AUC, area under the ROC curve; ICA, invasive coronary angiography; FFR, fractional flow reserve; NA, not available.

cation, due to the influence of partial volume effect and beam-hardening artifacts, there is a great difference between the measured CT value and the actual value, which will lead to the inaccuracy of the measurement results. In addition, the TAG results are also affected by coronary collateral circulation. Therefore, there is a need to maintain the stability of the CT value of the contrast agent during the scanning process. The Chinese scholars Wang et al. [8] compared TAG with corrected contrast opacification (TAG-CCO) with FFR, and revealed that CCTAbased TAG and TAG-CCO could not predict coronary artery functional stenosis. Bom et al. [9] reported that TAG, TAG-CCO, and transluminal diameter gradient did not discriminate between vessels with or without ischemia as defined by either PET or FFR. Hence, TAG or TAGCCO combined with CCTA could not significantly improve the diagnosis of coronary artery functional stenosis.

\section{Stress Dynamic CT Myocardial Perfusion Imaging}

In 1980, some scholars first attempted to study CT myocardial perfusion. With the development of related equipment, this technology has gradually become ma- ture. Dual-energy CT myocardial perfusion imaging technology provides additional information about myocardial tissue composition compared with conventional single-energy CT (Fig. 1). Dual-energy CT enables evaluating the myocardial blood supply by mapping iodine distribution within the myocardium. The combined use of CCTA and CT myocardial perfusion imaging can simultaneously assess the anatomical structure and physiological functions of the coronary artery [10-20] (Table 1).

The CT myocardial perfusion imaging includes reststress CT perfusion (CTP) and dynamic CTP. The reststress CTP can obtain only one sample data, and the presence of severe CAD on CCTA may unmask balanced ischemia undetected by rest-stress CTP imaging. In stress dynamic CT myocardial perfusion imaging, the myocardial ischemia state is induced by adenosine or ATP loading. Stress dynamic CT myocardial perfusion imaging can accurately evaluate the myocardial ischemia state $[21,22]$. Abnormal results of the measurement suggest that there is myocardial ischemia in the epicardium or microcirculation [23]. In at least $10-30 \%$ of patients with angina pectoris, no significant stenosis has been detected by invasive angiography, while $50-65 \%$ of these patients may have microcirculation ischemia [24-26]. A clinical trial re- 
Table 2. Diagnostic efficacy of CT-FFR in different studies

\begin{tabular}{|c|c|c|c|c|c|c|c|c|c|}
\hline Research & Time & Software & Types & $\begin{array}{l}\text { Reference } \\
\text { criteria }\end{array}$ & $\begin{array}{l}\text { Sensitivity, } \\
\%\end{array}$ & $\begin{array}{l}\text { Specificity, } \\
\%\end{array}$ & $\begin{array}{l}\text { Positive } \\
\text { prediction, \% }\end{array}$ & $\begin{array}{l}\text { Negative } \\
\text { prediction, \% }\end{array}$ & AUC \\
\hline $\begin{array}{l}\text { Koo et al. [31] } \\
\text { (DISCOVER-FLOW) }\end{array}$ & 2011 & HeartFlow & Multicenter prospective & Invasive FFR & 93 & 82 & 85 & 91 & 0.75 \\
\hline $\begin{array}{l}\text { Min et al. [32] } \\
\text { (DEFACTO) }\end{array}$ & 2012 & HeartFlow & Multicenter prospective & Invasive FFR & 90 & 54 & 67 & 84 & 0.80 \\
\hline $\begin{array}{l}\text { Nørgaard et al. } \\
\text { [33] (NXT) }\end{array}$ & 2014 & HeartFlow & Multicenter prospective & Invasive FFR & 86 & 79 & 65 & 93 & 0.90 \\
\hline Kim et al. [34] & 2014 & HeartFlow & Multicenter prospective & Invasive FFR & 85 & 57 & 83 & 62 & - \\
\hline Renker et al. [35] & 2014 & Siemens cFFR & Single-center retrospective & Invasive FFR & 94 & 84 & 65 & 93 & 0.91 \\
\hline Coenen et al. [36] & 2015 & Siemens cFFR & Single-center retrospective & Invasive FFR & 88 & 65 & 65 & 88 & 0.83 \\
\hline De Geer et al. [37] & 2015 & Siemens cFFR & Single-center retrospective & Invasive FFR & 83 & 76 & 56 & 83 & NA \\
\hline Baumann et al. [38] & 2016 & Meta-analysis & Meta-analysis & Invasive FFR & 89 & 70 & 69 & 90 & 0.87 \\
\hline Wu et al. [39] & 2016 & Meta-analysis & Meta-analysis & Invasive FFR & 89 & 76 & NA & NA & NA \\
\hline Kruk et al. [40] & 2016 & Siemens cFFR & Single-center prospective & Invasive FFR & 76 & 72 & 67 & 80 & 0.83 \\
\hline Coenen et al. [41] & 2016 & Siemens cFFR & Multicenter prospective & Invasive FFR & 82 & 60 & 65 & 79 & 0.78 \\
\hline Yang et al. [42] & 2017 & Siemens cFFR & Single-center prospective & Invasive FFR & 87 & 77 & 71 & 90 & 0.89 \\
\hline Kishi et al. [43] & 2018 & Toshiba CT FFR & Single-center retrospective & Invasive FFR & 95 & 82 & NA & NA & 0.953 \\
\hline Freiman et al. [44] & 2018 & Philips FFRct & Single-center retrospective & Invasive FFR & 88 & 79 & 79 & 88 & 0.91 \\
\hline
\end{tabular}

vealed that compared to SPECT-MPI or MRI-MPI, adenosine stress dynamic CTP has a similar accuracy in detecting myocardial perfusion defects. CTP is based on repeated imaging during the first-pass contrast agent inflow. However, De Geer et al. [27] reported that large variations in CTP blood flow suggest that a cutoff value for stress myocardial blood flow is inadequate to detect ischemic segments, and dynamic CTP was hampered by a limited coverage. Table 1 presents the published literatures on stress dynamic CT myocardial perfusion imaging in recent years. These data reveal that compared with the reference standard, CT myocardial perfusion imaging also has good sensitivity and specificity. Gao et al. [28] revealed that MBF and MBV were significantly lower in the abnormal perfusion group than in the normal perfusion group, and the differences were statistically significant. Wang et al. [29] explored the diagnostic value of the one-stop imaging of stress dynamic CT myocardial perfusion imaging combined with coronary CTA for coronary heart disease.

For patients who need direct measurement of the myocardial perfusion level or patients whose images have poor quality, TAG or CT-FFR cannot yield accurate results. Hence, patients with severe calcification of the cor- onary artery, as well as patients with suspected coronary artery disease and negative invasive angiography results, stress dynamic CT myocardial perfusion imaging should be the first choice. At present, Lubbers et al. [30] conducted a multicenter study named CRESCENT-II, where the process of one-stop stress myocardial perfusion imaging was optimized. For patients with suspected stable chest pain, the first scanning was performed to calculate the coronary artery calcium score. For patients with a positive coronary artery calcium score, CCTA was carried out. If $>50 \%$ stenosis was found in CCTA, stress myocardial perfusion imaging was performed. The study revealed that the optimized process provided a fast and efficient alternative for the function test.

\section{Computed Tomography-Fractional Flow Reserve}

Under normal circumstances, there is no obvious resistance when blood flow is conducted through the epicardial coronary artery, that is, the intravascular pressure remains constant from near to far. However, as blood flows downstream, resistance will be increased and pressure will be de- 


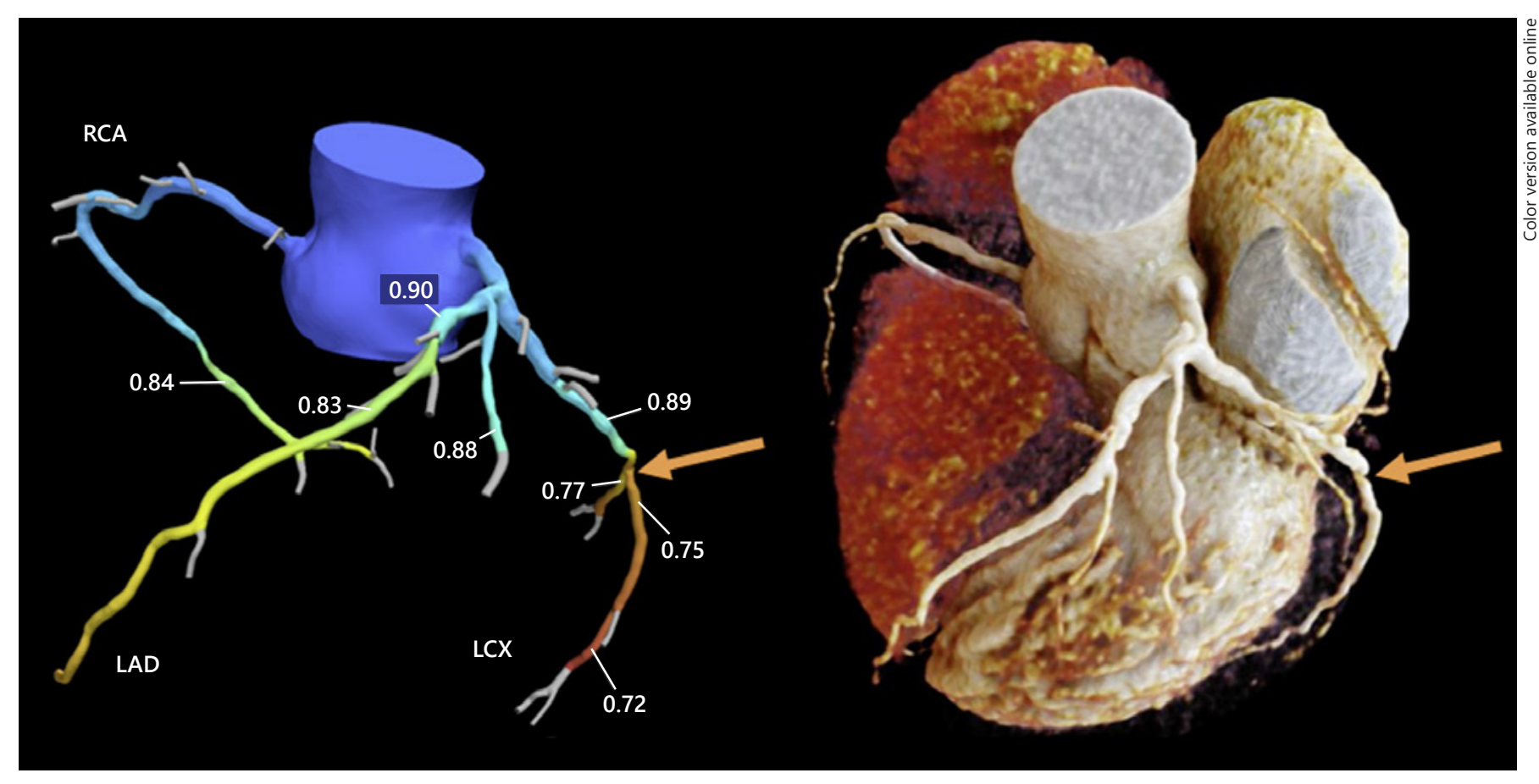

Fig. 2. CT-FFR image. A plaque at mid CX (arrow); the CT-FFR is 0.77.

creased. FFR refers to the ratio of maximal blood flow in the stenotic vessel to the maximum blood flow in the normal vessel under the same condition. This was first proposed by Dr. Pijls in 1993. FFR is an index to calculate coronary blood flow through pressure measurement. It is presently recognized as a functional evaluation index to evaluate the influence of coronary artery stenosis on blood flow.

In 2014, the United States Food and Drug Administration (FDA) approved the application of a new software system (FFR-CT) of HeartFlow for the noninvasive calculation of FFR. Different from traditional cardiac catheterization, the software can detect coronary artery obstruction by noninvasive examination, and assess the coronary blood flow of coronary heart disease patients who have symptoms or signs.

Table 2 summarizes the diagnostic efficiency of CTFFR in studies published in recent years. Among these, the DISCOVER-FLOW research published by Koo et al. [31] was the first multicenter prospective clinical trial to evaluate the diagnostic efficacy of CT-FFR. A total of 103 patients were included in that study, and the CCTA revealed at least one coronary artery with $\geq 50 \%$ stenosis. The diagnosis effect of CT-FFR was significantly higher than those of CCTA in terms of the accuracy of predicting coronary artery stenosis, positive predictive value, and negative predictive value. CT-FFR also has a good corre- lation with invasive FFR $(r=0.678, p<0.001)$. Furthermore, the DeFACTO Trial [32] evaluated the diagnostic value of CT-FFR and CCTA for moderate coronary artery stenosis (30-69\%). The results revealed that the negative predictive value of CT-FFR was higher than that of CCTA. Therefore, ischemic lesions requiring revascularization could be effectively screened to avoid unnecessary intervention. In the 2014 NXT research [33], a more accurate CT reconstruction technology and CT-FFR analysis software were adopted, and more strict quality control was required in the operation process of CCTA, in which all patients were required to use $\beta$-receptor blockers to control the heart rate to $<65 \mathrm{bpm}$ before CCTA, and were sublingually administered with nitroglycerin to expand the coronary artery. Moreover, the study included some patients with severe calcification, and it was found that the accuracy of CT-FFR prediction was not affected. Furthermore, due to the improvement of quality control in the process of CCTA and the analysis software, the specificity of CT-FFR was much better than that in previous multicenter studies, and had a better correlation with invasive FFR $(r=0.82, p<0.001)$ [31-44] (Table 2).

A study revealed that CT-FFR could provide additional information for biomechanics in plaques, such as plaque stress, plaque strain, and radial gradient [45]. These factors play certain roles in the occurrence and pro- 
gression of plaques [46]. This CT-FFR-derived biomechanical information is better in predicting acute coronary syndrome (ACS) than in predicting stenotic and high-risk plaques (the area under the curve is $0.727,0.675$, and 0.673 , respectively; Fig. 2). In addition, CT-FFR also provides an incremental risk stratification tool. Lipid plaques with a large necrotic core and positive remodeling have been proven to be correlated to FFR $<0.8$, and are independent of the degree of stenosis of the lumen. This has been proven to be an independent predictor of ACS $[47,48]$. A recent study named ADVANCE [49] revealed that the abnormal rate detected by CT-FFR was significantly higher in patients with $>3$ risk factors than in patients with $<3$ risk factors. Furthermore, the multivariate analysis revealed that underlying diabetes and hypertension could predict CT-FFR abnormality.

For interpretable patients with coronary stenosis, CTFFR should be the first choice in assessing for myocardial blood supply. FFR analysis based on CT data can evaluate the epicardial ischemia, but has limited efficacy for the evaluation of microcirculation ischemia [50]. In particular, it cannot be used to evaluate the suspected coronary heart disease patients with negative invasive angiography results. In addition, the application of CTA data for FFR analysis requires a specialized software and a long time duration. In addition, FFR analysis has a higher requirement than CTA data, which affects its routine clinical application.

\section{Conclusion}

The functional imaging of cardiac CT expands the field of cardiac CT imaging. In addition to the morphological assessment of the coronary artery, it can evaluate and test the blood supply of the myocardium. The reasonable application of these techniques can better predict myocardial ischemia, guide clinical treatment, and mon- itor the clinical curative effect. It has been considered that with the progress of technology, CT-FFR and CT myocardial perfusion combined with CCTA may become a powerful assessment tool for cardiovascular diseases, and will be very valuable for the accurate diagnosis of patients with suspected coronary heart disease. Cardiac CT functional imaging technology is worthy of clinical promotion and application.

\section{Statement of Ethics}

This study was conducted in accordance with the Declaration of Helsinki and with approval from the Ethics Committee of The First People's Hospital Kashgar Region. A written informed consent was obtained from all participants.

\section{Disclosure Statement}

The authors have no conflicts of interest to declare.

\section{Funding Sources}

This work was supported by the Grass-roots unit scientific and technological personnel training project in Xinjiang Autonomous Region (QN2016JC0292).

\section{Author Contributions}

X.-W.T. and A.-L.M. conceptualized and designed the study, drafted the initial manuscript, and reviewed and revised the manuscript. R.-B.Z., L.-J.J., and Y.H. designed the data collection instruments, collected data, carried out the initial analyses, and reviewed and revised the manuscript. X.-G.Z. coordinated and supervised data collection and critically reviewed the manuscript for important intellectual content. All authors approved the final manuscript as submitted and agree to be accountable for all aspects of the work.

\section{References}

1 Yang X, Li J, Hu D, Chen J, Li Y, Huang J, et al. Predicting the 10-Year Risks of Atherosclerotic Cardiovascular Disease in Chinese Population: The China-PAR Project (Prediction for ASCVD Risk in China). Circulation. 2016 Nov;134(19):1430-40.

2 Bettencourt N, Rocha J, Ferreira N, Pires-Morais G, Carvalho M, Leite D, et al. Incremental value of an integrated adenosine stress-rest MDCT perfusion protocol for detection of obstructive coronary artery disease. J Cardiovasc Comput Tomogr. 2011 Nov-Dec;5(6): 392-405.
3 Steigner ML, Mitsouras D, Whitmore AG, Otero HJ, Wang C, Buckley O, et al. Iodinated contrast opacification gradients in normal coronary arteries imaged with prospectively ECG-gated single heart beat 320-detector row computed tomography. Circ Cardiovasc Imaging. 2010 Mar;3(2):179-86.

4 Choi JH, Min JK, Labounty TM, Lin FY, Mendoza DD, Shin $\mathrm{DH}$, et al. Intracoronary transluminal attenuation gradient in coronary $\mathrm{CT}$ angiography for determining coronary artery stenosis. JACC Cardiovasc Imaging. 2011 Nov;4(11):1149-57.
5 Choi JH, Koo BK, Yoon YE, Min JK, Song YB, Hahn JY, et al. Diagnostic performance of intracoronary gradient-based methods by coronary computed tomography angiography for the evaluation of physiologically significant coronary artery stenoses: a validation study with fractional flow reserve. Eur Heart J Cardiovasc Imaging. 2012 Dec;13(12):1001-7. 
6 Yoon YE, Choi JH, Kim JH, Park KW, Doh JH, Kim YJ, et al. Noninvasive diagnosis of ischemia-causing coronary stenosis using CT angiography: diagnostic value of transluminal attenuation gradient and fractional flow reserve computed from coronary CT angiography compared to invasively measured fractional flow reserve. JACC Cardiovasc Imaging. 2012 Nov;5(11):1088-96.

7 Wong DT, Ko BS, Cameron JD, Nerlekar N, Leung MC, Malaiapan Y, et al. Transluminal attenuation gradient in coronary computed tomography angiography is a novel noninvasive approach to the identification of functionally significant coronary artery stenosis: a comparison with fractional flow reserve. J Am Coll Cardiol. 2013 Mar;61(12):1271-9.

8 Wang YK, Hou Y, Ma Y. Diagnostic value of corrected transluminal contrast attenuation gradient in coronary computed tomography angiography for the evaluation of physiologically significant coronary artery stenosis. J China Clin Med Imaging. 2016;27:713-7.

9 Bom MJ, Driessen RS, Stuijfzand WJ, Raijmakers PG, Van Kuijk CC, Lammertsma AA, et al. Diagnostic Value of Transluminal Attenuation Gradient for the Presence of Ischemia as Defined by Fractional Flow Reserve and Quantitative Positron Emission Tomography. JACC Cardiovasc Imaging. 2019 Feb; 12(2):323-33.

10 Bastarrika G, Ramos-Duran L, Rosenblum MA, Kang DK, Rowe GW, Schoepf UJ. Adenosine-stress dynamic myocardial CT perfusion imaging: initial clinical experience. Invest Radiol. 2010 Jun;45(6):306-13.

11 Weininger M, Schoepf UJ, Ramachandra A, Fink C, Rowe GW, Costello P, et al. Adenosine-stress dynamic real-time myocardial perfusion CT and adenosine-stress first-pass dual-energy myocardial perfusion CT for the assessment of acute chest pain: initial results. Eur J Radiol. 2012 Dec;81(12):3703-10.

12 Wang Y, Qin L, Shi X, Zeng Y, Jing H, Schoepf UJ, et al. Adenosine-stress dynamic myocardial perfusion imaging with second-generation dual-source CT: comparison with conventional catheter coronary angiography and SPECT nuclear myocardial perfusion imaging. AJR Am J Roentgenol. 2012 Mar;198(3):521-9.

13 Greif M, von Ziegler F, Bamberg F, Tittus J, Schwarz F, D'Anastasi M, et al. CT stress perfusion imaging for detection of haemodynamically relevant coronary stenosis as defined by FFR. Heart. 2013 Jul;99(14):1004-11.

14 Huber AM, Leber V, Gramer BM, Muenzel D, Leber A, Rieber J, et al. Myocardium: dynamic versus single-shot CT perfusion imaging. Radiology. 2013 Nov;269(2):378-86.

15 Rossi A, Dharampal A, Wragg A, Davies LC, van Geuns RJ, Anagnostopoulos C, et al. Diagnostic performance of hyperaemic myocardial blood flow index obtained by dynamic computed tomography: does it predict functionally significant coronary lesions? Eur Heart J Cardiovasc Imaging. 2014 Jan;15(1): 85-94.
16 Bamberg F, Marcus RP, Becker A, Hildebrandt K, Bauner K, Schwarz F, et al. Dynamic myocardial CT perfusion imaging for evaluation of myocardial ischemia as determined by MR imaging. JACC Cardiovasc Imaging. 2014 Mar;7(3):267-77.

17 Wong DT, Ko BS, Cameron JD, Leong DP, Leung MC, Malaiapan Y, et al. Comparison of diagnostic accuracy of combined assessment using adenosine stress computed tomography perfusion + computed tomography angiography with transluminal attenuation gradient + computed tomography angiography against invasive fractional flow reserve. J Am Coll Cardiol. 2014 May;63(18):1904-12.

18 Yang DH, Kim YH, Roh JH, Kang JW, Han D, Jung J, et al. Stress Myocardial Perfusion CT in Patients Suspected of Having Coronary Artery Disease: Visual and Quantitative Analysis-Validation by Using Fractional Flow Reserve. Radiology. 2015 Sep;276(3):715-23.

19 Coenen A, Rossi A, Lubbers MM, Kurata A, Kono AK, Chelu RG, et al. Integrating CT Myocardial Perfusion and CT-FFR in the Work-Up of Coronary Artery Disease. JACC Cardiovasc Imaging. 2017 Jul;10(7):760-70.

20 Pontone G, Baggiano A, Andreini D, Guaricci AI, Guglielmo M, Muscogiuri G, et al. Stress Computed Tomography Perfusion Versus Fractional Flow Reserve CT Derived in Suspected Coronary Artery Disease: the PERFECTION Study. JACC Cardiovasc Imaging. 2019 Aug;12(8 Pt 1):1487-97.

21 Sørgaard MH, Kofoed KF, Linde JJ, George RT, Rochitte CE, Feuchtner G, et al. Diagnostic accuracy of static CT perfusion for the detection of myocardial ischemia. A systematic review and meta-analysis. J Cardiovasc Comput Tomogr. 2016 Nov - Dec;10(6):450-7.

22 Carrascosa P, Capunay C. Myocardial CT perfusion imaging for ischemia detection. Cardiovasc Diagn Ther. 2017 Apr;7(2):112-28.

23 van de Hoef TP, Siebes M, Spaan JA, Piek JJ. Fundamentals in clinical coronary physiology: why coronary flow is more important than coronary pressure. Eur Heart J. 2015 Dec; 36(47):3312-9a.

24 Reis SE, Holubkov R, Lee JS, Sharaf B, Reichek $\mathrm{N}$, Rogers WJ, et al. Coronary flow velocity response to adenosine characterizes coronary microvascular function in women with chest pain and no obstructive coronary disease. Results from the pilot phase of the Women's Ischemia Syndrome Evaluation (WISE) study. J Am Coll Cardiol. 1999 May;33(6): 1469-75.

25 Graf S, Khorsand A, Gwechenberger M, Novotny $\mathrm{C}$, Kletter $\mathrm{K}$, Sochor H, et al. Typical chest pain and normal coronary angiogram: cardiac risk factor analysis versus PET for detection of microvascular disease. J Nucl Med. 2007 Feb;48(2):175-81.

26 Murthy VL, Naya M, Foster CR, Hainer J, Gaber M, Di Carli G, et al. Improved cardiac risk assessment with noninvasive measures of coronary flow reserve. Circulation. 2011 Nov; 124(20):2215-24.
27 De Geer J, Gjerde M, Brudin L, Olsson E, Persson A, Engvall J. Large variation in blood flow between left ventricular segments, as detected by adenosine stress dynamic CT perfusion. Clin Physiol Funct Imaging. 2015 Jul; 35(4):291-300.

28 Gao Y, Wang CY, Zhou YL, et al. Stress dynamic CT myocardial perfusion imaging combined with coronary CT angiography for the detection of ischemic coronary artery disease. Zhonghua Fang She Xue Za Zhi. 2017; 51:246-50.

29 Wang J, Chen HW, Fang XM, et al. The diagnostic value of dual source coronary CT angiography combined with dynamic CT myocardial perfusion imaging in coronary artery disease. Zhonghua Fang She Xue Za Zhi. 2017; 51:251-6.

30 Lubbers M, Coenen A, Kofflard M, Bruning T, Kietselaer B, Galema T, et al. Comprehensive Cardiac CT With Myocardial Perfusion Imaging Versus Functional Testing in Suspected Coronary Artery Disease: The Multicenter, Randomized CRESCENT-II Trial. JACC Cardiovasc Imaging. 2018 Nov; 11(11): 1625-1636.

31 Koo BK, Erglis A, Doh JH, Daniels DV, Jegere $\mathrm{S}$, Kim HS, et al. Diagnosis of ischemia-causing coronary stenoses by noninvasive fractional flow reserve computed from coronary computed tomographic angiograms. Results from the prospective multicenter DISCOVER-FLOW (Diagnosis of Ischemia-Causing Stenoses Obtained Via Noninvasive Fractional Flow Reserve) study. J Am Coll Cardiol. 2011 Nov;58(19):1989-97.

32 Min JK, Leipsic J, Pencina MJ, Berman DS, Koo BK, van Mieghem C, et al. Diagnostic accuracy of fractional flow reserve from anatomic CT angiography. JAMA. 2012 Sep; 308(12):1237-45.

33 Nørgaard BL, Leipsic J, Gaur S, Seneviratne S, Ko BS, Ito H, et al.; NXT Trial Study Group. Diagnostic performance of noninvasive fractional flow reserve derived from coronary computed tomography angiography in suspected coronary artery disease: the NXT trial (Analysis of Coronary Blood Flow Using CT Angiography: Next Steps). J Am Coll Cardiol. 2014 Apr;63(12):1145-55.

34 Kim KH, Doh JH, Koo BK, Min JK, Erglis A, Yang HM, et al. A novel noninvasive technology for treatment planning using virtual coronary stenting and computed tomography-derived computed fractional flow reserve. JACC Cardiovasc Interv. 2014 Jan;7(1):72-8.

35 Renker M, Schoepf UJ, Wang R, Meinel FG, Rier JD, Bayer RR 2nd, et al. Comparison of diagnostic value of a novel noninvasive coronary computed tomography angiography method versus standard coronary angiography for assessing fractional flow reserve. Am J Cardiol. 2014 Nov;114(9):1303-8. 
36 Coenen A, Lubbers MM, Kurata A, Kono A, Dedic A, Chelu RG, et al. Fractional flow reserve computed from noninvasive $\mathrm{CT}$ angiography data: diagnostic performance of an onsite clinician-operated computational fluid dynamics algorithm. Radiology. 2015 Mar; 274(3):674-83.

37 De Geer J, Sandstedt M, Björkholm A, Alfredsson J, Janzon M, Engvall J, et al. Software-based on-site estimation of fractional flow reserve using standard coronary CT angiography data. Acta Radiol. 2016 Oct;57(10): 1186-92.

38 Baumann S, Renker M, Hetjens S, Fuller SR, Becher T, Loßnitzer D, et al. Comparison of coronary computed tomography ahngiography-derived vs invasive fractional flow reserve assessment: meta-analysis with subgroup evaluation of intermediate stenosis. Acad Radiol. 2016 Nov;23(11):1402-11.

39 Wu W, Pan DR, Foin N, Pang S, Ye P, Holm $\mathrm{N}$, et al. Noninvasive fractional flow reserve derived from coronary computed tomography angiography for identification of ischemic lesions: a systematic review and metaanalysis. Sci Rep. 2016 Jul;6(1):29409.

40 Kruk M, Wardziak Ł, Demkow M, Pleban W, Pręgowski J, Dzielińska Z, et al. Workstationbased calculation of CTA based FFR for intermediate stenosis. JACC Cardiovasc Imaging. 2016 Jun;9(6):690-9.
41 Coenen A, Lubbers MM, Kurata A, Kono A, Dedic A, Chelu RG, et al. Coronary CT angiography derived fractional flow reserve: methodology and evaluation of a point of care algorithm. J Cardiovasc Comput Tomogr. 2016 Mar-Apr;10(2):105-13.

42 Yang DH, Kim YH, Roh JH, Kang JW, Ahn JM, Kweon J, et al. Diagnostic performance of on-site CT-derived fractional flow reserve versus CT perfusion. Eur Heart J Cardiovasc Imaging. 2017 Apr;18(4):432-40.

43 Kishi S, Giannopoulos AA, Tang A, Kato N, Chatzizisis YS, Dennie C, et al. Fractional Flow Reserve Estimated at Coronary CT Angiography in Intermediate Lesions: Comparison of Diagnostic Accuracy of Different Methods to Determine Coronary Flow Distribution. Radiology. 2018 Apr;287(1):76-84.

44 Freiman M, Nickisch H, Schmitt H, Maurovich-Horvat P, Donnelly PM, Vembar M, et al. A functionally personalized boundary condition model to improve estimates of fractional flow reserve with CT (CT-FFR). Med Phys. 2018 Mar;45(3):1170-7.

45 Nørgaard BL, Leipsic J, Koo BK, Zarins CK, Jensen JM, Sand NP, et al. Coronary computed tomography angiography derived fractional flow reserve and plaque stress. Curr Cardiovasc Imaging Rep. 2016;9(1):2.
46 Choi G, Lee JM, Kim HJ, Park JB, Sankaran S, Otake $\mathrm{H}$, et al. Coronary artery axial plaque stress and its relationship with lesion geometry: application of computational fluid dynamics to coronary CT angiography. JACC Cardiovasc Imaging. 2015 Oct;8(10):115666.

47 Narula J, Nakano M, Virmani R, Kolodgie FD, Petersen R, Newcomb R, et al. Histopathologic characteristics of atherosclerotic coronary disease and implications of the findings for the invasive and noninvasive detection of vulnerable plaques. J Am Coll Cardiol. 2013 Mar;61(10):1041-51.

48 Ahmadi A, Stone GW, Leipsic J, Serruys PW, Shaw L, Hecht H, et al. Association of Coronary Stenosis and Plaque Morphology With Fractional Flow Reserve and Outcomes. JAMA Cardiol. 2016 Jun;1(3):350-7.

49 Kitabata H, Leipsic J, Patel MR, Nieman K, De Bruyne B, Rogers C, et al. Incidence and predictors of lesion-specific ischemia by FFRCT: learnings from the international ADVANCE registry. J Cardiovasc Comput Tomogr. 2018 Mar - Apr;12(2):95-100.

50 Gaur S, Taylor CA, Jensen JM, Bøtker HE, Christiansen EH, Kaltoft AK, et al. FFR Derived From Coronary CT Angiography in Nonculprit Lesions of Patients With Recent STEMI. JACC Cardiovasc Imaging. 2017 Apr;10(4):424-33. 